\title{
Rentabilidade Econômica do Arrendamento de Terra para Cultivo de Eucalipto em São Paulo
}

\author{
Vanderlei Santos de Souza ${ }^{1}$, Romano Timofeiczyk Junior ${ }^{2}$, Ricardo Berger ${ }^{2}$, \\ João Carlos Garzel Leodoro da Silva ${ }^{2}$, Philippe Delacote ${ }^{3}$ \\ ${ }^{1}$ Departamento Operacional, Empresa ERB - Energias Renováveis, Curitiba/PR, Brasil \\ ${ }^{2}$ Departamento de Economia Rural e Extensão, Universidade Federal do Paraná - UFPR, Curitiba/PR, Brasil \\ ${ }^{3}$ Laboratoire d’Economie Forestière, Inra-AgroParisTech, Nancy, França
}

\section{RESUMO}

O presente estudo teve como objetivo analisar o arrendamento de terra para o cultivo de eucalipto no Vale do Paraíba, São Paulo. Utilizaram-se informações de dez propriedades, sendo oito proprietários da terra, uma empresa de papel e celulose e um investidor em ativos florestais. As ferramentas econômicas utilizadas foram VPL, TIR e VET. Com uma TMA de $8,75 \%$ a.a., o cultivo de eucalipto com investimento em terra na região estudada mostrou ser viável economicamente em cinco propriedades. Com a garantia de produtividade estabelecida em contrato, o investimento apresentou viabilidade econômica para o arrendamento de terra, porém inviável para o investidor. A garantia de produtividade mostrou ser importante para manter a rentabilidade para o investidor e para o arrendado pois, sem a mesma, apenas três propriedades apresentaram viabilidade econômica para arrendamento.

Palavras-chave: avaliação econômica, preço da terra, arrendamento florestal.

\section{Economic Profitability of Land Lease for Eucalyptus Cultivation in Sao Paulo State, Brazil}

\begin{abstract}
The present study aimed to analyze the leasing of land for the cultivation of eucalyptus in Vale do Paraiba, Sao Paulo state, Brazil. We used information from 10 properties, eight landowners, a pulp and paper company, and an investor in forestry assets. The economic tools used were the Net Present Value (NPV), Internal Rate of Return (IRR) and Land Expectation Value (LEV). Considering a minimum attractiveness rate of $8.75 \%$, the cultivation of eucalyptus with investment in land in the study area was economically viable for only five of the properties analyzed. With the guarantee of productivity established in the contract, the investment was feasible for land lease, but uneconomical for the investor. Ensuring productivity was important to maintain economic viability for the investor and the lessee, considering that without productivity assurance only three properties showed economic viability for land lease.
\end{abstract}

Keywords: economic evaluation, land price, forestry lease. 


\section{INTRODUÇÃO}

O desempenho econômico do setor florestal está intimamente ligado a capacidade de produção de madeira, sua principal matéria-prima. De acordo com dados da Associação Brasileira de Produtores de Florestas Plantadas (ABRAF, 2012), o Brasil possui aproximadamente 6,5 milhões de hectares com cultivos florestais, principalmente com pinus e eucalipto. A madeira produzida nesses cultivos é a principal fonte de matéria-prima para o abastecimento do setor moveleiro, celulose, madeira serrada, lenha, painéis e siderurgia. Dos 255 milhões de metros cúbicos de madeira consumidos pelas indústrias do setor em 2011, 36\% foram pela indústria de papel e celulose.

Uma alternativa encontrada pelo setor para suprir a demanda crescente por madeira são parcerias para o cultivo florestal, tornando-se uma prática estratégica para as empresas de celulose e papel. Localizadas geralmente em áreas com preço de terra elevado para a atividade florestal, veem na parceria com produtores rurais uma alternativa para o aumento da sua base florestal. De acordo com a Associação Brasileira de Celulose e Papel (BRACELPA, 2011), o segmento de papel e celulose possui $28,7 \%$ de sua floresta sob forma de fomento, principalmente com pequenos produtores rurais, representando uma área de aproximadamente 377 mil hectares. O estado de São Paulo detém a terceira maior área plantada com pinus e eucalipto em parceria, sendo que do total de áreas sob fomento e arrendamento com essas espécies, $18 \%$ estão no estado de São Paulo, somando 161,5 mil hectares (ABRAF, 2012).

Uma das explicações para o aumento de parcerias para a formação florestal está no alto investimento em terras. De acordo com o Anuário da Agricultura Brasileira (FNP, 2010), o estado de São Paulo possui o hectare de terra para reflorestamento mais caro do país. Rezende \& Oliveira (2001) mencionam que o custo de oportunidade da terra representa aproximadamente $5 \%$ do custo total de produção florestal no Brasil, sendo que pode aumentar de acordo com o valor das terras. Conforme Silva et al. (2008), se se considerar ainda que as áreas de preservação permanente e de reserva legal não poderiam ser utilizadas para a produção de madeira, o custo da terra pode chegar a $15 \%$ ou mais do custo de produção, dependendo da topografia ou particularidade da região.

Para o desenvolvimento de qualquer atividade econômica, três fatores são preponderantes: terra, capital e trabalho. No caso da atividade florestal para as empresas, o fator terra encarece a produção pela imobilização de capital para sua aquisição, através dos impostos e custos de produção, além do problema social gerado pela concentração fundiária. Por outro lado, para o proprietário rural que se encontra no raio de atuação de uma empresa florestal, o fomento pode representar uma oportunidade, facilitada pelo aporte de tecnologia e apoio financeiro para a entrada na atividade, nas diferentes modalidades de parceria (Rochadelli et al., 2008).

Dessa forma, as parcerias florestais cumprem com três funções básicas: (1) Suprimento de madeira para a indústria de papel e celulose; (2) Possibilitar a investidores institucionais empregar recursos financeiros em florestas plantadas, sem a necessidade de imobilizar capital em terra; e (3) Para o proprietário rural, a oportunidade de gerar receita, seja em consórcio com as atividades já existentes ou mesmo em áreas marginais, sem aptidão para outros usos.

Cada uma das partes envolvidas tem como principal objetivo obter o máximo retorno econômico possível. A parceria para investimentos florestais, conforme Oliveira et al. (2006), constitui componente importante na renda familiar do produtor rural. Ainda de acordo com os autores, é possível inferir que essa condição se dá pelo fato da fomentadora pagar antecipadamente ao produtor para ele repassar ao empreiteiro, responsável pela execução de serviços pertinentes à implantação, manutenção e colheita florestal. Porém, em muitos casos os serviços são executados pelos próprios membros da família do produtor.

Além de suprir os interesses individuais, a parceria florestal traz ganhos sociais e ambientais, de forma a tornar o setor florestal mais produtivo e, ao mesmo tempo, contribuir para o desenvolvimento de toda região em que está inserido. Os benefícios dessas parcerias são de interesse do setor privado, governo e sociedade.

Para a indústria, que necessita de madeira, um programa de fomento florestal é visto como uma possibilidade de retorno do investimento em matériaprima, a custos compatíveis, e também uma forma de propiciar uma melhoria em sua imagem com as parcerias formadas. Para governo e sociedade, por sua vez, tais programas cumprem certa função social gerando impostos, empregos e favorecendo a fixação da mão de obra na região. Além disso, a exploração de florestas plantadas contribui para diminuir a pressão 
antrópica sobre as florestas nativas, favorecendo sua preservação e conservação, possibilitando também a recuperação de áreas degradadas (Oliveira, 2003).

A prática florestal pelo pequeno e médio produtor rural atua na melhor distribuição das áreas com plantios comerciais, servindo como um mecanismo para desconcentração fundiária (Fischer, 2007). Com o aumento da prática de parcerias para o plantio de florestas comerciais no Brasil, cresce a necessidade de estudos para a avaliação econômica dessas parcerias. Timofeiczyk et al. (2007) citam que existem várias ferramentas para análise de rentabilidade de investimentos em projetos de longo prazo. Segundo os autores, no caso de investimentos florestais, as mais tradicionais são a do Valor Presente Líquido (VPL), Valor Presente Líquido Anualizado (VPLa), Taxa Interna de Retorno (TIR) e Valor Esperado da Terra (VET). Com o uso dessas ferramentas, o presente trabalho teve como objetivo principal analisar a rentabilidade econômica do cultivo de eucalipto na região do Vale do Paraíba, no estado de São Paulo, sob sistemas de parceria.

\section{MATERIAL E MÉTODOS}

\section{1. Área de estudo}

O trabalho foi realizado no Vale do Paraíba, estado de São Paulo. A área de estudo é composta por dez propriedades, compreendendo um total de $1.030 \mathrm{ha}$, onde 668 ha são de áreas aproveitáveis com destino ao cultivo florestal de uma indústria de celulose e papel. Com o objetivo de estimular a oferta de madeira para suas unidades de produção, a empresa de celulose e papel incentivou o arrendamento para o cultivo de plantios comerciais através da participação de pequenos e médios produtores rurais da região. Para tanto, a empresa de celulose e papel buscou a parceria com investidores institucionais para o cultivo florestal.

Dessa forma, o arrendamento atende as necessidades de cada um de seus participantes. A empresa produtora de celulose e papel tem a garantia do fornecimento de madeira para a operação de sua unidade de produção. O proprietário rural, que já possui a terra, garante uma receita com a atividade florestal. Para o investidor, a vantagem está em estabelecer um investimento com garantia de receita para seus acionistas e a não imobilização do capital em terra. Esse conjunto de ações possibilita à empresa produtora de celulose e papel reduzir consideravelmente a imobilização de capital, tanto em terra como em floresta. Para a manutenção do arrendamento de terra, podem-se estabelecer como principais direitos e deveres de cada uma das partes:

a) Produtor rural (arrendado): O proprietário rural cede a porção de terra para o cultivo de eucalipto, em troca tem direito a $30 \%$ de todo o volume de madeira colhido em sua propriedade. Do volume total de madeira a que tem direito, assume a obrigação de comercializar com o arrendatário.

b) Empresa de celulose e papel (arrendatário): A empresa é responsável pela implantação e manutenção florestal, assumindo $20 \%$ de todo o desembolso necessário para a implantação florestal e 100\% do custo total com a manutenção dos plantios implantados nas áreas arrendadas. Ainda são de total responsabilidade do arrendatário os serviços para manter a sanidade dos plantios, incluindo mão de obra e outros custos, licenciamentos ambientais e inventário florestal.

O arrendatário garante a compra de toda a madeira produzida sob sua responsabilidade nas áreas arrendadas. Ainda é garantia da empresa uma produtividade mínima de $280 \mathrm{~m}^{3}$ de madeira por hectare aos sete anos. Para toda a madeira comprada pelo arrendatário, o preço mínimo é estipulado em contrato para o metro cúbico de madeira para processo (maiores diâmetros) e para lenha (menores diâmetros). Os valores foram corrigidos de acordo com o Índice Geral de Preços (IGP-M), da Fundação Getúlio Vargas (FGV). O arrendatário tem a obrigação de comprar toda a madeira produzida, pelo preço estabelecido em contrato. Ainda tem o direito a $22 \%$ do volume total de madeira produzido nas áreas arrendadas.

c) Investidor: Para reduzir os custos com novos projetos florestais, buscaram-se os recursos financeiros necessários através de parcerias. No caso dos arrendamentos florestais da empresa, a solução foi a parceria com investidores que tenham em projetos florestais seu principal foco de aplicação financeira. O investidor institucional tem a responsabilidade de arcar com $80 \%$ de todo o desembolso realizado na implantação florestal. Esse valor realizado dá o direito a $48 \%$ de todo o volume de madeira produzido nas áreas arrendadas. Para reduzir os valores com transporte de madeira, o arrendamento é realizado nas proximidades da fábrica, com 
distâncias máximas de $90 \mathrm{~km}$. O contrato tem validade até a colheita, podendo ser renovado ou não a cada intervenção na floresta, desde que todas as partes assim o queiram.

\subsection{Dados utilizados}

Os dados para composição do estudo foram obtidos junto à empresa de celulose e papel. Foi realizada consulta aos documentos referentes aos dados físicos e econômicos, bem como às condições para a implantação do cultivo florestal. O período de coleta dos dados foi de setembro a dezembro de 2010, com rechecagem e informações complementares obtidas após o período de coleta dos dados, estendendo-se até final de 2012. A fonte de dados foi fornecida pela empresa, através de mapas de uso do solo, inventários, planos de manejo, contratos de arrendamento florestal e planilhas de custos.

\subsection{Fluxo de caixa}

Utilizou-se o modelo de fluxo de caixa descontado, o qual considera a variação que o dinheiro possui ao longo do tempo. Horngren (1985) menciona que esse é o melhor método para tomadas de decisão, sendo que um aspecto importante do fluxo de caixa descontado é seu enfoque nas entradas e saídas de caixa e não no lucro líquido, tal como calculado no sentido de contabilidade pelo regime de competência.

Com base nos custos totais com implantação e manutenção florestal, preços de madeira e produtividade, foram elaborados o fluxo de caixa para o investimento sem e com a aquisição de terra. Dessa forma, a análise possibilitou avaliar economicamente o investimento para cada um dos participantes do arrendamento. $\mathrm{O}$ arrendatário e o investidor não arcam com o valor da terra, custeando apenas um percentual do custo com a implantação e manutenção da florestal. Já o arrendado não arca com os investimentos necessários para a formação da floresta, porém, tem no valor da terra seu investimento.

Com base no valor médio da madeira no Vale do Paraíba, o preço estipulado em contrato para o metro cúbico de madeira nas áreas arrendadas foi corrigido pelo IGP-M para a data da colheita.

O fluxo de caixa com a inclusão do valor da aquisição da terra parte do pressuposto que o custo no ano zero com a terra refere-se à sua compra, ou seja, saída de capital para aquisição de um hectare de terra. No último ano do fluxo de caixa, correspondente à receita proveniente da venda de madeira em pé, é acrescido também à receita a venda da terra, e isso se deve ao fato de que a terra é vendida, entrando como receita no fluxo de caixa. Bittencourt (2006), analisando a viabilidade econômica do Nim Indiano, com investimento inicial em terra, utilizou seu valor como saída de caixa no ano zero e no final do ciclo como entrada de caixa.

\subsection{Taxa mínima de atratividade (TMA)}

A TMA utilizada no presente trabalho foi de $8,75 \%$ a.a., a mesma utilizada como pagamento dos juros por empréstimos junto à linha de financiamento do Programa de Plantio Comercial e Recuperação de Floresta. Isso parte do pressuposto de que o investimento dever ser remunerado a uma taxa no mínimo igual às cobradas pelos principais financiamentos florestais.

\subsection{Métodos de análise de investimentos}

Após a obtenção do fluxo de caixa contendo as entradas e saídas monetárias ao longo do horizonte de planejamento, utilizaram-se ferramentas da engenharia econômica para avaliação da rentabilidade. Os métodos utilizados foram os métodos do Valor Presente Líquido (VPL), Valor Esperado da Terra (VET) e Taxa Interna de Retorno (TIR).

\subsection{Valor Presente Líquido (VPL)}

Expresso em valores monetários e largamente utilizado para medir a eficiência econômica de um investimento, é obtido através da soma algébrica dos valores, descontados do fluxo de caixa, segundo a taxa mínima de atratividade adotada. De acordo com Timofeiczyk (2004), o VPL pode ser expresso pela Equação 1:

$V P L=\sum_{j=0}^{n} R j(1+i)^{-j}-\sum_{J=0}^{n} C j(1+i)^{-j}$

Em que: $\mathrm{Rj}=$ Receitas no período de tempo $\mathrm{j}$ considerado; $\mathrm{Cj}=$ Custos no período de tempo $\mathrm{j}$ considerado; $\mathrm{n}=$ Duração do projeto em anos ou em número de períodos de tempo; $\mathrm{i}=$ Taxa anual de juros, expressa de forma decimal. 


\subsection{Taxa interna de retorno (TIR)}

A TIR é alcançada quando o VPL do fluxo de caixa se iguala a zero. Fornece a taxa da real rentabilidade do investimento e por essa razão é considerada a taxa interna do empreendimento. Segundo Timofeiczyk (2004), a TIR é obtida pela Equação 2:

$$
T I R=\sum_{j=0}^{n} R j(1+i)^{-j}-\sum_{j=0}^{n} C j(1+i)^{-j}=0
$$

Em que: $\mathrm{Rj}=$ Receitas do período de tempo $\mathrm{j}$ considerado; $\mathrm{C} \mathbf{j}=$ Custos do período de tempo $\mathrm{j}$ considerado; $\mathrm{n}=$ Duração do projeto em anos ou em número de períodos de tempo.

\subsection{Valor esperado da terra (VET)}

Davis \& Johnson (1987) afirmam que o VET é o valor que expressa o VPL de uma área de terra nua a ser utilizada para a produção de madeira, calculado com base numa série infinita de rotações. Esse critério é utilizado para determinar a rotação econômica e o preço máximo de compra de terra nua, considerando-se uma série infinita. De acordo com Silva et al. (2002), o VET é obtido pela Equação 3:

$$
V E T=\frac{\sum_{j=0}^{n}\left[(R j-C j)(1+i)^{n}\right]}{(1+i)^{n}-1}
$$

Em que: $\mathrm{VET}=$ Valor esperado da terra; $\mathrm{Rj}=$ Receitas líquidas descontadas; $\mathrm{C}$ = Custos totais descontados; $\mathrm{i}$ = Taxa de desconto; $\mathrm{n}=$ Idade de rotação da floresta.

Timofeiczyk (2004) comenta que para ocorrer um excedente econômico a TIR do investimento florestal deve ser maior do que a TMA. $\mathrm{O}$ autor afirma que o excedente passa a ser o quanto pode ser gasto para adquirir a terra ou o valor máximo que se pode gastar nela e ainda permitir a remuneração dos fatores e do proprietário.

\section{RESULTADOS E DISCUSSÃO}

\subsection{Custos}

As parcerias florestais, quando realizadas com empresas de grande porte como as do setor de papel e celulose, podem ter nos custos com implantação florestal uma vantagem. Com vasta experiência no cultivo de florestas de rápido crescimento, essas empresas geralmente possuem uma grande estrutura que permite economia de escala, o que pode acarretar em custos menores. A região do Vale do Paraíba possui condições edafoclimáticas propícias para a produção florestal. Isso facilita o cultivo de eucalipto como alternativa de fonte de renda para os agricultores.

Porém, a região possui uma grande diversidade de tipos de solo que, em razão das características que cada um apresenta, exigem tratamentos diferenciados, variando de acordo com as exigências nutricionais de cada um. As propriedades analisadas apresentaram variações no custo de implantação, principalmente pelas diferenças existentes na formação do relevo. De acordo com Oliveira et al. (2006), quanto mais acidentado o terreno, maior os custos com a atividade florestal.

Na Tabela 1 são apresentados os custos totais, distribuídos de acordo com as operações necessárias à implantação e manutenção de um hectare de floresta de eucalipto, dada as condições da área estudada. Os custos variaram de acordo com a propriedade estudada, tendo como principal fator as condições do terreno.

As propriedades com os maiores custos de implantação $(4,6,8,9$ e 10) são as que apresentam piores condições de relevo. Os solos apresentam características diferentes para cada área arrendada, implicando em diferentes recomendações de adubação, com impactos nos custos de insumos. Os custos com manutenção são diferentes para cada ano após o plantio, devido menor necessidade com operações de roçada e capina com o amadurecimento do plantio (Dubè, 1999).

Do valor total do custo com a formação florestal, 87\% foi com a implantação e $13 \%$ com a manutenção. O valor correspondente a manutenção, que foi todo de responsabilidade do arrendatário, representou $43 \%$ do seu custo total, comprometidos na formação florestal. A diferença do maior valor, referente à propriedade 4, em relação ao menor, da propriedade 1 , foi em função dos maiores custos com estradas, limpeza de área e insumos.

\subsection{Receitas}

Timofeiczyk (2004) afirma que o volume produzido por uma floresta é um dos principais componentes para a formação da receita. Cercado de muita incerteza, geralmente é um grande inibidor para parcerias de longo prazo. Uma alternativa encontrada para o 
arrendamento nesse trabalho foi a garantia de um volume mínimo quando da colheita. Assim, nas florestas que não atingirem o volume de $280 \mathrm{~m}^{3} /$ ha, o arrendatário garante o pagamento equivalente ao volume da garantia. $\mathrm{O}$ volume garantido pelo arrendatário de $40 \mathrm{~m}^{3} / \mathrm{ha}$ ao ano é compatível com a produtividade média dos plantios de eucalipto no Brasil, que, de acordo com a BRACELPA (2011), produzem $41 \mathrm{~m}^{3} /$ ha, com potencial para $50 \mathrm{~m}^{3} / \mathrm{ha}$.

A Tabela 2 apresenta as receitas brutas descontadas para o ano zero, a uma taxa de $8,75 \%$ a.a. Considerando que para os cultivos nas áreas que não atingiram o volume mínimo de madeira estipulado em contrato a multiplicação pelo preço da madeira é sobre o volume da garantia. Dessa forma, a receita do arrendatário representa a subtração das receitas do investidor e do arrendado da receita total com a madeira produzida nas áreas arrendadas. Além da demanda da madeira para processo, há também demanda de madeira em forma de lenha, utilizada como energia em caldeiras.

Da receita bruta total com a venda da madeira em pé, após a distribuição dos percentuais sobre o volume de madeira a que o investidor e o arrendado têm direito, de acordo com a garantia, o percentual restante do arrendatário foi de 16\%. Nota-se que o arrendatário custeia a madeira a que tem direito de acordo com o contrato, porém parte dela é utilizada para garantir o volume prometido para o investidor e o arrendatário. A receita bruta total, dada a garantia de produtividade, ao final ficaria distribuída em 51\%

Tabela 1. Custos totais ( $\mathrm{R} \$ / \mathrm{ha})$ com implantação e manutenção florestal.

Table 1. Total cost $(\mathrm{R} \$ /$ ha) with deploying and maintaining forest.

\begin{tabular}{|c|c|c|c|c|c|c|c|c|}
\hline \multirow[b]{2}{*}{ Propriedades } & Ano 0 & Ano 1 & Ano 2 & Ano 3 & Ano 4 & Ano 5 & Ano 6 & Ano 7 \\
\hline & $\begin{array}{c}\text { Implantação } \\
\text { florestal (R\$/ha) }\end{array}$ & \multicolumn{7}{|c|}{ Manutenção florestal (R\$/ha) } \\
\hline 1 & $(3.695)$ & (141) & (92) & (74) & $(62)$ & (62) & (62) & - \\
\hline 2 & $(3.920)$ & $(150)$ & (98) & (78) & (65) & (65) & (65) & - \\
\hline 3 & $(3.973)$ & (147) & (99) & (79) & (66) & (66) & (66) & - \\
\hline 4 & $(4.855)$ & (151) & $(121)$ & (97) & (81) & $(81)$ & (81) & - \\
\hline 5 & (3.793) & (145) & $(95)$ & (76) & (63) & (63) & (63) & - \\
\hline 6 & $(4.510)$ & (153) & (113) & (90) & (75) & (75) & (75) & - \\
\hline 7 & $(3.730)$ & (142) & (93) & (75) & (62) & (62) & (62) & - \\
\hline 8 & $(4.144)$ & (149) & (103) & (83) & (69) & (69) & (69) & - \\
\hline 9 & $(4.362)$ & (145) & (109) & (87) & (73) & (73) & (73) & - \\
\hline 10 & $(4.188)$ & $(151)$ & (105) & $(84)$ & (70) & (70) & (70) & - \\
\hline Total & $(41.169)$ & (1.477) & (1.028) & (823) & $(686)$ & $(686)$ & $(686)$ & - \\
\hline
\end{tabular}

Fonte: Elaborado pelos autores (2012).

Tabela 2. Receita bruta da venda de madeira em pé com as garantias de contrato ( $\mathrm{R} \$$ ).

Table 2. Gross revenue from the sale of standing timber with the guarantees of the contract (R\$).

\begin{tabular}{|crrrrrrrrr}
\multirow{2}{*}{ Propriedades } & \multicolumn{2}{c}{ Total } & \multicolumn{2}{c}{ Investidor } & \multicolumn{2}{c}{ Arrendado } & \multicolumn{2}{c|}{ Arrendatário } \\
\cline { 2 - 10 } & Processo & Lenha & Processo & Lenha & Processo & Lenha & Processo & Lenha \\
\hline 1 & 98.741 & 4.773 & 47.396 & 2.291 & 29.622 & 1.432 & 21.723 & 1.050 \\
2 & 749.903 & 43.715 & 386.998 & 22.559 & 241.874 & 14.100 & 121.031 & 7.055 \\
\hline 3 & 305.992 & 18.611 & 177.062 & 10.769 & 110.664 & 6.731 & 18.265 & 1.111 \\
\hline 4 & 335.430 & 20.402 & 183.386 & 11.154 & 114.616 & 6.971 & 37.428 & 2.276 \\
\hline 5 & 245.870 & 14.333 & 126.885 & 7.397 & 79.303 & 4.623 & 39.682 & 2.313 \\
\hline 6 & 823.664 & 48.014 & 425.063 & 24.778 & 265.665 & 15.487 & 132.936 & 7.749 \\
\hline 7 & 359.095 & 41.332 & 198.057 & 22.796 & 123.785 & 14.248 & 37.253 & 4.288 \\
\hline 8 & 190.549 & 11.108 & 98.336 & 5.732 & 61.460 & 3.583 & 30.754 & 1.793 \\
\hline 9 & 436.304 & 26.537 & 209.426 & 12.738 & 130.891 & 7.961 & 95.987 & 5.838 \\
\hline 10 & 557.529 & 18.888 & 267.614 & 9.066 & 167.259 & 5.666 & 122.656 & 4.155 \\
\hline
\end{tabular}

Fonte: Elaborado pelos autores (2012). 
para o investidor, $33 \%$ para o arrendado e $16 \%$ para $\mathrm{o}$ arrendatário.

\subsection{Análise econômica para o cultivo de eucalipto}

Quando não foi realizado o investimento em terra, os resultados apresentaram retorno econômico satisfatório. O VPL médio encontrado foi de R $\$ 2.015 /$ ha e TIR de $14,8 \%$ a.a. (Tabela 3 ). Os valores encontrados para o VPL com sinal positivo mostram que o projeto, sem o investimento em terra, possui valor das receitas maior que o dos custos, considerando a TMA utilizada. A TIR calculada para todas as propriedades mostrou-se maior que a TMA, indicando que o investimento em eucalipto nessas condições possui rentabilidade maior que a taxa de remuneração alternativa do capital. Resultados semelhantes foram encontrados por Rezende \& Oliveira (2001).

Com o investimento em terra, a TIR do projeto caiu em média $40 \%$, com uma taxa de retorno inferior à TMA utilizada (Tabela 3). A aquisição de terra para o cultivo de eucalipto, considerando as condições apresentadas no trabalho, mostra que a rentabilidade ficará abaixo da expectativa de retorno do capital. Isso pode ser verificado pelo fato de o VPL médio para as propriedades ter assumido valor negativo, comprovando que a TIR calculada foi menor que a TMA (Tabela 3). Portanto, os resultados reforçam a melhor opção das grandes empresas de base florestal pelo arrendamento ao invés de adquirirem terra para a realização de plantios próprios.

Após considerar o investimento em terra, metade das propriedades analisadas teve sua TIR reduzida a valores inferiores a TMA, indicando que seu retorno não é mais viável quando considerada a taxa de desconto utilizada. As propriedades 1, 2, 5, 9 e 10, mesmo com a redução na TIR, mantiveram seus valores acima da TMA, respectivamente com $11 \%, 9 \%, 9,4 \%, 9,1 \%$ e $9,7 \%$.

O valor médio da terra no Vale do Paraíba, no estado de São Paulo é de R $\$ 4.549$ por hectare. O VET para as propriedades estudadas ficou na média em $\mathrm{R} \$ 4.537$ por hectare, o que indica que em média a atividade florestal não é economicamente viável ao preço de terra vigente na região, considerando todas as premissas adotadas.

As propriedades que apresentaram valores de VET por hectare compatíveis com a atividade foram: 1 (R \$ 7.548), 2 ( $\mathrm{R} \$ 4.897), 5$ ( $\mathrm{R} \$ 5.213), 9(\mathrm{R} \$ 4.983)$ e 10 ( $\mathrm{R} \$ 5.824)$. Conhecendo os resultados para a viabilidade econômica do cultivo de eucalipto na região de estudo, pode ser realizada a análise econômica individual para cada um dos participantes no arrendamento florestal. De acordo com o critério do VPL, os valores individuais são apresentados na Tabela 4 , com os resultados para o investidor, arrendatário e arrendado.

O investidor obteve na média um VPL negativo em $\mathrm{R} \$ 13,00$ por hectare o que, de acordo com esse critério, mostra que o investimento não é viável

Tabela 3. Valor presente líquido, taxa interna de retorno e valor esperado da terra para o cultivo de eucalipto na região do Vale do Paraíba, estado de São Paulo, com e sem investimento em terra.

Table 3. Net Present Value, Internal Rate of Return and Expected Value of the Earth, for the cultivation of eucalyptus in the Vale do Paraíba, São Paulo, with and without investment in land.

\begin{tabular}{|c|c|c|c|c|c|}
\hline \multirow{2}{*}{ Propriedades } & \multicolumn{2}{|c|}{ SIT } & \multicolumn{2}{|c|}{ CIT } & \multirow{2}{*}{ VET (R\$/ha) } \\
\hline & TIR (\%) & VPL (R\$/ha) & TIR (\%) & VPL (R\$/ha) & \\
\hline 1 & $18,7 \%$ & 3.312 & $11,0 \%$ & 1.292 & 7.458 \\
\hline 2 & $15,5 \%$ & 2.175 & $9,0 \%$ & 155 & 4.897 \\
\hline 3 & $13,3 \%$ & 1.411 & $7,6 \%$ & (609) & 3.178 \\
\hline 4 & $11,0 \%$ & 802 & $6,7 \%$ & $(1.218)$ & 1.807 \\
\hline 5 & $16,0 \%$ & 2.315 & $9,4 \%$ & 295 & 5.213 \\
\hline 6 & $13,2 \%$ & 1.540 & $7,9 \%$ & $(480)$ & 3.468 \\
\hline 7 & $14,9 \%$ & 1.856 & $8,4 \%$ & $(164)$ & 4.179 \\
\hline 8 & $14,6 \%$ & 1.936 & $8,6 \%$ & $(84)$ & 4.358 \\
\hline 9 & $15,02 \%$ & 2.213 & $9,1 \%$ & 193 & 4.983 \\
\hline 10 & $16,1 \%$ & 2.587 & $9,7 \%$ & 567 & 5.824 \\
\hline Média & $14,8 \%$ & 2.015 & $8,7 \%$ & (5) & 4.537 \\
\hline
\end{tabular}

CIT $=$ Com investimento em terra; SIT $=$ Sem investimento em terra. Fonte: Elaborado pelos autores (2012). 
economicamente. $\mathrm{O}$ arrendado, para as duas situações em relação ao investimento em terra, apresentou VPL positivo, indicando de maneira geral que para o arrendamento de terra no Vale do Paraíba a atividade florestal remunera a taxas maiores que a TMA utilizada.

Para o arrendatário, o VPL calculado foi negativo em R $\$ 185,00$ por hectare, indicando que de acordo com esse critério não é viável economicamente (Tabela 4). Para o arrendatário, fica claro que a garantia de produtividade inviabiliza o arrendamento.

Para todas as propriedades analisadas que não alcançaram a produtividade mínima de 280 metros cúbicos por hectare, o investimento mostrou não ser viável do ponto de vista econômico para todos os critérios utilizados na análise. Para o investidor, que tem a produtividade de madeira garantida pela empresa de celulose e papel, o custo de implantação florestal foi decisivo para os resultados encontrados. As propriedades com menores VPL são as que tiveram os maiores custos com implantação florestal.

Para o arrendado, o fator preponderante para os resultados em termos de VPL foi a produtividade de cada propriedade, com valores líquidos presentes maiores para as que obtiveram um volume de madeira maior que o da garantia.

A Tabela 5 apresenta os valores de acordo com o critério da TIR para cada um dos envolvidos no arrendamento florestal. De acordo com os resultados obtidos, o arrendado e o arrendatário apresentaram TIR, na média, maior que a TMA. O investidor obteve

Tabela 4. Valor presente líquido em $\mathrm{R} \$ /$ ha, para investidor, arrendatário e arrendado, com e sem investimento em terra.

Table 4. Net Present Value for the Investor in $\mathrm{R} \$ /$ ha, and Leased Tenant, with and without investment in land.

\begin{tabular}{|ccccc|}
\hline & Investidor & Arrendatário & \multicolumn{2}{c|}{ Arrendado } \\
\cline { 3 - 5 } & & & SIT & CIT \\
\hline 1 & 503 & 501 & 2.654 & 198 \\
\hline 3 & 126 & $(145)$ & 2.510 & 78 \\
\hline 4 & 79 & $(861)$ & 2.508 & 76 \\
\hline 5 & $(648)$ & $(764)$ & 2.508 & 76 \\
\hline 6 & 231 & $(106)$ & 2.510 & 78 \\
\hline 7 & $(360)$ & $(307)$ & 2.510 & 78 \\
\hline 8 & 222 & $(517)$ & 2.465 & 70 \\
\hline 9 & $(59)$ & $(205)$ & 2.510 & 84 \\
\hline 10 & $(230)$ & 233 & 2.517 & 142 \\
\hline
\end{tabular}

SIT $=$ Sem investimento em terra; CIT $=$ Com investimento em terra. Fonte: Elaborado pelos autores (2012).

Tabela 5. Taxa interna de retorno anual para investidor, arrendatário e arrendado, com garantia de produtividade. Table 5. Internal Rate of Annual Return for the Investor, Tenant and Leasehold, and with guarantee of productivity.

\begin{tabular}{cccc}
\hline Propriedades & Investidor & Arrendatário & Arrendado \\
\hline 1 & $11,1 \%$ & $10,6 \%$ & $9,4 \%$ \\
\hline 2 & $9,3 \%$ & $13,3 \%$ & $9,0 \%$ \\
3 & $9,1 \%$ & $13,1 \%$ & $9,0 \%$ \\
4 & $6,0 \%$ & $9,8 \%$ & $9,0 \%$ \\
\hline 5 & $9,9 \%$ & $14,0 \%$ & $9,0 \%$ \\
\hline 6 & $7,2 \%$ & $11,0 \%$ & $9,0 \%$ \\
\hline 7 & $9,8 \%$ & $13,9 \%$ & $9,0 \%$ \\
\hline 8 & $8,5 \%$ & $12,4 \%$ & $9,0 \%$ \\
\hline 9 & $7,7 \%$ & $11,4 \%$ & $9,0 \%$ \\
\hline Média & $8,8 \%$ & $11,0 \%$ & $9,2 \%$ \\
\hline
\end{tabular}

Fonte: Elaborado pelos autores (2012). 
em média valores abaixo da TMA, indicando que o investimento como um todo não está sendo remunerado dentro das expectativas.

Os valores da TIR do investidor abaixo da TMA foram consequência principalmente dos resultados calculados para as propriedades 4 (6\%), $6(7 \%), 8(8 \%)$ e 9 (8\%). Considerando a TIR média para o investidor sem a participação dessas propriedades seu valor foi de 10\%. Dessa forma, de acordo com esse critério, não seria recomendado ao investidor a renovação do contrato de arrendamento para essas propriedades.

$\mathrm{O}$ arrendado, diferentemente do investidor, não tem a possibilidade de optar por outra propriedade, visto que a terra é sua e nela está imobilizado seu capital. Porém, considerando a garantia de produtividade, todas as propriedades apresentaram rentabilidade econômica, ou seja, TIR maior que a TMA.

\section{CONCLUSÕES}

- Considerando uma taxa mínima de atratividade de 8,75\% a.a., de acordo com os dados analisados, o cultivo de eucalipto com investimento em terra na região do Vale do Paraíba mostrou não ser atrativo economicamente. Para essa taxa de desconto, apenas cinco propriedades apresentaram TIR maior que a TMA.

- Considerando a garantia de produtividade estabelecida em contrato, o investimento como um todo se mostrou viável economicamente para o arrendamento de terra.

- O arrendatário, considerando a garantia de produtividade, apresentou TIR menor que a TMA para todas as propriedades que obtiveram produção de madeira menor que a da garantia. A parceria somente é viável economicamente com uma produtividade real média maior que a apresentada.

- Para a garantia de produtividade, todas as propriedades foram economicamente atrativas, de acordo com o critério da TIR, para o arrendamento da terra.

- A garantia de produtividade mostrou-se importante para manter a atratividade econômica para o investidor e para o arrendado.

\section{STATUS DA SUBMISSÃO}

Recebido: 5 mar., 2013

Aceito: 4 mar., 2015

\section{AUTOR(ES) PARA CORRESPONDÊNCIA}

\section{Romano Timofeiczyk Junior}

Departamento de Economia Rural e Extensão, Universidade Federal do Paraná - UFPR, Av. Prefeito Lothário Meissner, 632, Jardim Botânico, CEP 80420-030, Curitiba, PR, Brasil

e-mail: romano.timo@gmail.com

\section{REFERENCIAS}

Associação Brasileira de Celulose e Papel - BRACELPA. Relatório Estatístico 2011. Brasília; 2011. [cited 2013 Jan 7]. Available from: http:// http://www.bracelpa.org.br/bra2/ sites/default/files/public/RA02-RelatorioFlorestal_2010.pdf.

Associação Brasileira dos Produtores de Florestas Plantadas - ABRAF. Anuário Estatístico 2012, ano base 2011. Brasília; 2012. [cited 2013 Jan 7]. Available from: http://www.abraflor.org.br.

Bittencourt AM. O cultivo do NIM indiano (azadirachta indica a. juss): uma visão econômica [dissertação]. Curitiba: Setor de Ciências Agrárias, Universidade Federal do Paraná; 2006.

Davis LS, Johnson KN. Forest management. New York: McGrawn Hill, 1987.

Dubè F. Estudos técnicos e econômicos de sistemas agroflorestais com Eucalyptus SP no noroeste do Estado de Minas Gerais: o caso da companhia mineira de metais [dissertação]. Viçosa: Setor de Ciências Agrárias, Universidade Federal de Viçosa; 1999.

Fischer A. Incentivos em programas de fomento florestal na indústria de celulose [tese]. São Paulo: Departamento de Administração, Universidade de São Paulo; 2007.

Horngren CT. Introdução à contabilidade gerencial. 5. ed. Rio de Janeiro: Prentice-Hall do Brasil; 1985.

Informa Economics - FNP. AGRIANUAL: anuário da agricultura brasileira 2010. São Paulo: FNP; 2010.

Oliveira AD, Valverde SR, Coelho FMC. Aspectos de relevância econômica no fomento florestal a partir da percepção dos produtores rurais envolvidos. Revista Árvore 2006; 30(4): 593-601. http://dx.doi.org/10.1590/ S0100-67622006000400012.

Oliveira PRS. Diagnóstico e indicadores de sustentabilidade em fomento florestal no Estado do Espírito Santo [tese]. Viçosa: Universidade Federal de Viçosa; 2003.

Rezende JLP, Oliveira AD. Análise econômica e social de projetos florestais. Viçosa: UFV; 2001. 
Rochadelli R, Silva JCG, Rodrigues F, Schneider AV, Petla D. Expansão florestal via fomento no segundo planalto paranaense: uma abordagem através da estrutura fundiária das propriedades rurais da região. Revista Cerne 2008; 14(2): 163-169.

Silva ML, Jacovine LAG, Valverde SR. Economia florestal. Viçosa: Universidade Federal Viçosa; 2002. 178 p.

Silva ML, Rezende JLP, Lima Junior VB, Cordeiro SA, Coelho Junior LM. Métodos de cálculo do custo da terra na atividade florestal. Revista Cerne 2008; 14(1): 75-81.

Timofeiczyk R. Jr. Análise econômica do manejo de baixo impacto em florestas tropicais: um estudo de caso [tese]. Curitiba: Setor de Ciências Agrárias, Universidade Federal do Paraná; 2004.

Timofeiczyk R Jr, Berger R, Sousa RATM, Silva VSM. Custo de oportunidade da terra no manejo de baixo Impacto em florestas tropicais: um estudo de caso. Revista Floresta 2007; 37(3). 